\title{
How to write science
}

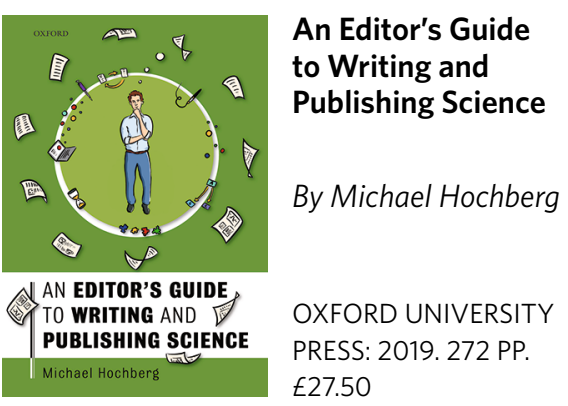

t may not seem the most enticing scientific topic for a book, but the process of writing and publishing science is one that every scientist has to learn and will spend their entire career undertaking. An inside guide to the process by the founding editor of one of ecology's major journals, Michael Hochberg of Ecology Letters, therefore has great potential to improve the lives of many scientists.

Michael Hochberg founded Ecology Letters in 1998 and served as chief editor for a decade. In that time, he would have handled hundreds of manuscripts, making initial assessments of them and taking a subset through peer review. He is also a practising population biologist with many published papers to his own name. He has written a comprehensive guide to the publishing process based on this experience.

The first third or so of the book is devoted to the writing process, from finding a productive working routine, to structuring the manuscript, to the appropriate use of language. The rest of the book guides the reader through the publishing process, from choosing a journal to interacting with editors to navigating peer review, and then moves onto more general observations on the publishing industry and the scientific endeavour, including the economics of journals and the push towards open data.
Overall, it's a fairly logical progression through these topics, albeit in a fairly conservative fashion (for example, when it comes to discussing the pros and cons of different journal models). This is exactly what is needed as a pragmatic guide for junior scientists, even if more established researchers might wish for more in-depth critical analysis in places. In terms of the writing process, the key message of the book is the use of models. Hochberg argues that writing good articles is made possible by carefully choosing some shining examples from the published literature and mimicking their style and structure (although obviously not their content - he wisely devotes a whole chapter to plagiarism!). He provides some pretty detailed examples of how models can be used, as well as a worked example of how to structure an abstract. Incidentally, his examples come almost exclusively from ecology, but I imagine they would be accessible enough to the general scientific reader.

It's worth a few comments on figures. I was somewhat disappointed that figures, which he acknowledges are of central importance in a manuscript, are discussed very briefly in a page or so, much less than is devoted to several somewhat more peripheral topics. However, he makes quite liberal use of figures to illustrate his own text. I have mixed feelings about this, because it's not a topic that easily lends itself to illustration, but if they were absent the book would appear very dry. While most of them are moderately useful, one does have to wonder if it's necessary to use an illustration of the rungs on a ladder to make the point that it's not always the first three invited reviewers who accept to review a manuscript.

In addition to the regular figures, the beginning of each chapter is illustrated with a cartoon by Alex Cagan, more famous for his excellent rapid illustration of conference talks. I fear this topic does not allow him to show us his very finest work, but it does undoubtedly liven up the feel of the book.

While such a book is never going to be a page-turner, there are some really interesting sections on the publishing process and it is very accessibly written. There are some useful insights into how editors think that can probably only be provided by an experienced editor, and it takes a realistic approach to the current and future challenges facing both authors and editors. I did wonder if just a couple of boxes on the issue of gender and geographical bias in the published literature was enough, but that is perhaps a topic for a different book; one that challenges the system rather than tries to guide the reader through it. The use of the female pronoun throughout when talking about a hypothetical scientist is certainly a nice touch, albeit one that I wish was not rare enough to remain noteworthy.

Figures aside, I have only a few minor quibbles about topics that could have been included, and this is the best guide to the overall process I have come across. When I was a student, undergraduate and graduate, none of these things were taught, and the whole process of publishing science was hardly discussed, despite its importance. This is starting to improve, but still the inclusion in university courses of modules on how to write and publish is patchy. If every doctoral student or junior researcher were to read this book, it would go a long way towards rectifying the situation. It might even make my own job easier.

Reviewed by Patrick Goymer Chief Editor, Nature Ecology \& Evolution. e-mail:p.goymer@nature.com

Published online: 21 October 2019 https://doi.org/10.1038/s41559-019-1016-X 